Article

\title{
Biofilm Formation of a Polymer Brush Coating with Ionic Liquids Compared to a Polymer Brush Coating with a Non-Ionic Liquid
}

\author{
Hideyuki Kanematsu ${ }^{1, *(\mathbb{D})}$, Atsuya Oizumi ${ }^{1}\left(\mathbb{D}\right.$, Takaya Sato ${ }^{2}{ }^{(}$, Toshio Kamijo ${ }^{2}$, Saika Honma ${ }^{2}$, \\ Dana M. Barry ${ }^{3,4}{ }^{\text {, Nobumitsu Hirai }}{ }^{1}$, Akiko Ogawa ${ }^{1}{ }^{1}$, Takeshi Kogo ${ }^{1}$, Daisuke Kuroda ${ }^{1}$, \\ Katsuhiko Sano ${ }^{5}{ }^{(D}$, Katsuhiko Tsunashima ${ }^{6}$, Seung-Hyo Lee ${ }^{7}$ and Myeong-Hoon Lee ${ }^{7}$ \\ 1 National Institute of Technology, Suzuka College, Suzuka, Mie 510-0294, Japan; \\ h25s11@ed.cc.suzuka-ct.ac.jp (A.O.); hirai@chem.suzuka-ct.ac.jp (N.H.); ogawa@chem.suzuka-ct.ac.jp (A.O.); \\ kougo@mse.suzuka-ct.ac.jp (T.K.); daisuke@mse.suzuka-ct.ac.jp (D.K.) \\ 2 National Institute of Technology, Tsuruoka College, Tsuruoka 997-8511, Japan; \\ takayasa@tsuruoka-nct.ac.jp (T.S.); kamijo@tsuruoka-nct.ac.jp (T.K.); saika@tsuruoka-nct.ac.jp (S.H.) \\ 3 Department of Electrical \& Computer Engineering, Clarkson University, Potsdam, NY 13699, USA; \\ dmbarry@clarkson.edu \\ 4 Science/Math Tutoring Center, SUNY Canton, Canton, NY 13617, USA \\ 5 D\&D Corporation, 7870, Sakura-cho, Yokkaichi, Mie 512-1211, Japan; sano@ddcorp.co.jp \\ 6 National Institute of Technology, Wakayama College, Gobo, Wakayama 644-0023, Japan; \\ tsunashima@wakayama-nct.ac.jp \\ 7 Division of Marine Engineering, Korea Maritime University, Busan 49112, Korea; \\ seunghyo0121@gmail.com (S.-H.L.); leemh@kmou.ac.kr (M.-H.L.) \\ * Correspondence: kanemats@mse.suzuka-ct.ac.jp; Tel.:+81-59-368-1848
}

Received: 28 August 2018; Accepted: 27 October 2018; Published: 13 November 2018

\begin{abstract}
N,N-diethyl-N-(2-methancryloylethy)-N-methylammonium bis(trifluoromethylsulfonyl) imide polymer (DEMM-TFSI) brush coated specimens (substrate: glasses) and a liquid ion type of polymer brush coating were investigated for their antifouling effect on biofilms. Biofilms were produced by two kinds of bacteria, E. coli and S. epidermidis. They were formed on specimens immersed into wells (of 12-well plates) that were filled with culture liquids and bacteria. The biofilm formation was observed. Also, brush coated specimens and glass substrates were investigated in the same way. DEMM polymer brush coated specimens formed more biofilm than PMMA (polymethyl methacrylate) polymer brush coated specimens and glass substrates. A greater amount of polarized components of biofilms was also observed for DEMM polymer brush coated specimens. The polar characteristics could be attributed to the attraction capability of bacteria and biofilms on DEMM polymer brush coated specimens. When considering the ease of removing biofilms by washing it with water, the ionic liquid type polymer brush (coated specimens) could be used for antifouling applications. If an initial antifouling application is needed, then the polar characteristics could be adjusted (design of the components and concentrations of ionic liquids, etc.) to solve the problem.
\end{abstract}

Keywords: biofilms; antifouling; DEMM; DEME; PMMA; polymer brush coating; polysaccharide; protein; lipid; nucleic acid; Raman spectroscopy

\section{Introduction}

For antifouling properties of materials, the surface plays an important role [1-10]. This is because fouling phenomena occur at materials' surfaces as a result of interactions between various materials and environments. The phenomena should be controlled from both the environmental surroundings 
and materials' surfaces. The causes of fouling can be grouped into two main categories of animate and inanimate causes [11]. As for the latter, one can mention many types of contamination from organic to inorganic matter. Usually, they are just called contaminants. The former is usually called biofouling [12,13]. Biofouling is a process where organisms generally attach to materials' surfaces and cause their function and/or characteristics to change and deteriorate in many cases. It can be further classified into microfouling (where microbes such as bacteria and microalgae attach to materials' surfaces) and macrofouling like the attachments of barnacles, oysters, and other bigger organisms in marine environments. For the biofouling in marine environments, microfouling is usually followed by macrofouling. Therefore, the microfouling should be controlled to suppress macrofouling $[14,15]$.

In the case of microfouling, microbial attachments are generally followed by biofilm formations [16-19]. Biofilms are matters formed by bacterial activities. Since microfouling is a process involving bacteria and other micro-organisms, biofilms play an important role. This formation process is well known, and it is one of biofouling. Biofilms are formed on materials' surfaces by multiple steps. Firstly, bacteria attach to materials' surfaces to get nutrition (carbon compounds) which generally exists on materials' surfaces as conditioning film. The repeated process of attachment and detachment occurs. If the attachment phenomenon exceeds the detachment process, then the number of bacteria on materials' surfaces begins to increase. When this number reaches a threshold value, a signal transduction phenomenon called quorum sensing occurs. At this time, the attached bacteria simultaneously excrete polysaccharides. As a result, materials' surfaces would be covered with sticky water films. These sticky water films are called biofilms and are actually the product of microfouling. Then, the biofilm with high water content, becomes a very complex matrix that contains microorganisms (extracellular polymeric substances, EPS). In most cases, they are proteins, nucleic acids, ions (organic, inorganic) and molecules, accumulated from the aqueous environment. Since the biofilm formation makes materials' surfaces sticky, various organic and inorganic contaminants could be attached and kept on materials' surfaces. To keep the materials' surfaces free from contaminants, biofilm formation should be controlled.

From the environmental side, chemical agents such as biocides, etc. might be effective countermeasures to control fouling. On the other hand, fouling could be controlled by using materials with appropriate coatings. The coating is important because it can make a new performance (anti-fouling in this case) expressed, while the inherent properties of the material would be kept.

We have investigated the biofilm formation behaviors for many kinds of materials using some unique evaluation methods and applied coating processes to antifouling effects [20-58]. In this experiment, we focused on a polymer brush coating for the anti-fouling effect. There are already many polymer brush coatings which have been investigated and proposed so far [59-61]. All of them have future possibilities from various viewpoints. The polymer brush we selected for this experiment was one made from an ionic liquid. By applying living radical polymerization to graft polymerization with the ionic liquid, some of the authors succeeded in producing concentrated polymer brushes [62-64]. The polymer brush has lots of attractive properties such as good adherence and water repellency. Particularly, this type of polymer brush has a very low friction coefficient, which may be useful to the automobile industry. Several of the authors have tried to apply it to the decoration of solid-state polymer electrolyte.

While such advanced functions and characteristics have been investigated, antifouling properties have not been closely studied yet. However, we are gradually learning that some researchers have proposed polymer brush coatings. A number of researchers believe that most of the fouling on materials' surfaces is a direct or indirect result of biofilms. Biofilms are formed by bacterial activities as previously described. However, they are different from bacteria. Since they are actually sticky water films on materials' surfaces, they may incorporate organic and inorganic components as they grow. This might result in serious fouling. Some researchers think that polymer brush coatings could be used to repel biofilms and related contaminants [65]. However, this strongly depends on the type of brush coating used and the results of the investigations performed. Therefore, we decided to use 
biofilms to test the ionic liquid brush coating that we developed. Such an additional characteristic (to make a material's surface free from contaminants due to anti-fouling effects) will improve the overall performance and broaden the field of applications.

\section{Materials and Methods}

In this experiment, we issued a polymer brush coating made from ionic liquid. $\mathrm{N}, \mathrm{N}$-diethyl-N-methyl-N-(2-methoxyethyl) ammonium bis(trifluoromethanesulfonyl) imide (DEME-TFSI). Some substituents were added to it and N,N-diethyl-N- (2-methancryloylethy)-Nmethylammonium bis(trifluoromethylsulfonyl) imide (DEMM-TFSI) was grafted on glass specimens $(10 \mathrm{~mm} \times 15 \mathrm{~mm})$ through surface-initiated living radical polymerization to get a densely grafting polymer brush coating [66,67]. Since the polymer coating was ionic, it was basically composed of a cationic part (DEMM) and an anionic one (TFSI). However, for this paper, it was called DEMM coating. On the other hand, a PMMA was coated as a reference [68]. In this paper, it was referred to as PMMA coating. It was made on the same size glass specimens through polymerization of methyl methacrylate by Activators Regenerated by Electron Transfer Atom Transfer Radical Polymerization (ARGET ATRP) process $[69,70]$. Glass has always been used for the general and start-up investigations by our research groups, since they are basically inactive and can avoid reactions between the substrates and solutions.

Our polymer coatings had to be swollen so that the surface would be brush-like. The polymer coating glasses were swollen using the following processes. DEMM coating specimens were immersed in acetonitrile solution for about $12 \mathrm{~h}$. Then the specimens were immersed in $50 \%$ water-50\% acetonitrile mixed solution for an hour. Finally, the specimens were immersed in water for $1 \mathrm{~h}$. As for the PMMA polymer coated specimens, they were immersed in tetrahydrofuran (THF) solution for about $12 \mathrm{~h}$. Then they were immersed in 50\% water-50\% THF solution for one hour and finally, they were immersed in water for one hour. Through these steps, surface coated polymers became brush-like coating on glass specimens. And since both polymer coatings were hydrophobic, such step-by-step substitution processes were needed. The number of specimens per each measurement was three $(N=3)$. We designed the polymer brush coating according to our previous studies [62-64,66-68]. The glass plate with the concentrated ionic liquid type polymer brush (the brush length: $500 \mathrm{~nm}$ in dry state and the graft density: 0.15 polymer chains $/ \mathrm{nm}^{2}$ ) was used in this test. The graft chain length, the graft density and the brush layer thickness were determined by the gel permeation chromatography [64], thermal decomposition analysis [64] and spectroscopic ellipsometry [66], respectively.

Two kinds of bacteria were used for biofilm formation and evaluation. One of them was Escherichia coli (E. coli, K-12, G6), a Gram-negative bacteria and the other was Staphylococcus epidermidis (S. epidermidis, ATCC 35984). Both are typical non-pathogenic bacteria as Gram-negative and Gram-positive bacteria, respectively. Therefore, they were the most suitable for the general investigation of biofilm formation. E. coli was cultured in LB (1\% tryptone- $0.5 \%$ yeast extract- $1 \%$ $\mathrm{NaCl})$ liquid broth in advance for $18 \mathrm{~h}( \pm 2 \mathrm{~h})$. On the other hand, S. epidermidis was cultured in Heart Infusion (HI) liquid broth ( $1 \%$ heart extract- $1 \%$ peptone- $0.5 \% \mathrm{NaCl}$ ) for $18 \mathrm{~h}( \pm 2 \mathrm{~h})$ in advance. Both were cultured at $37^{\circ} \mathrm{C}$ in a shaking incubator.

A biofilm study is generally composed of two steps. One of them is to artificially produce biofilms. On a laboratory scale, the environment to produce biofilms is called a "laboratory biofilm reactor". In this experiment, we chose a simple screening process using the 12-well plates. It is generally called the microtiter plate method. This method might provide bacteria with too much nutrition and may be a sort of deflection from the real environment. However, it could give us information for a simple, and rapid data screening process. Each specimen was placed in the well of a sterilized 12-Well plate. Each well was filled with liquid broths containing bacteria. In the case of E. coli, the plates were kept at $25^{\circ} \mathrm{C}$, so that the biofilm formation would be accelerated. On the other hand, the plates for S. epidermidis were kept at $37^{\circ} \mathrm{C}$. After one day $(24 \mathrm{~h})$ passed, the specimens were removed from the wells. Then, they were evaluated by using Raman spectroscopy combined with optical microscopy (NRS-3100, JASCO, Halifax, NS, Canada). Raman spectroscopy is a useful method to detect exopolymeric substances 
(EPS), which are excreted from bacteria and exist as one of the biofilm components. We decided to use the Raman method for this study because ionic interactions could take place using the staining technique with crystal violet solution.

\section{Results}

\subsection{Optical Microscopic Images}

All of the specimens were observed by a technique that used optical microscopy combined with the Raman spectroscopic analyzer. In Figure 1, optical microscopic images before and after the swelling process were shown for DEMM polymer brush specimens. All of them were observed in the perpendicular direction to specimens' surfaces. Before swelling (Figure 1a), the surface was pretty smooth. However, the roughness increased after swelling and the top of fiber-like brushes could be observed in Figure 1b. In the same way, PMMA specimens showed the top of brushes after swelling (Figure 2b), while they did not show any brushes before swelling (Figure 2a). These photos clearly show that polymer brush specimens were made on glass surfaces.

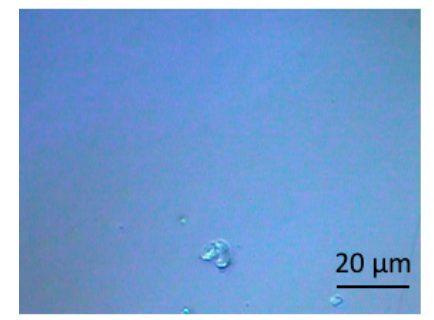

(a)

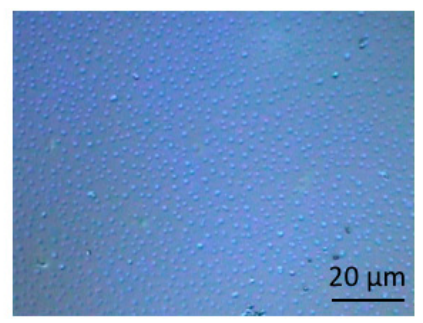

(b)

Figure 1. Optical microscopic images for N,N-diethyl-N-(2-methancryloylethy)-N-methylammonium bis(trifluoromethylsulfonyl) imide (DEMM-TFSI) specimens (a) before and (b) after selling process.

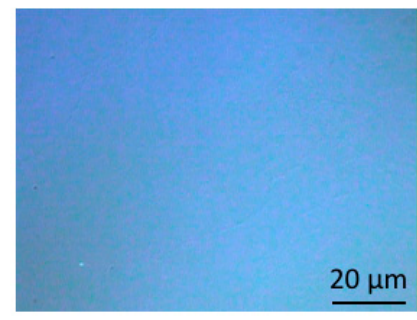

(a)

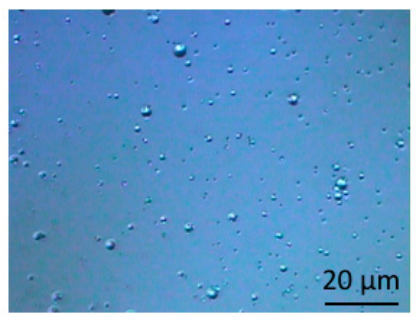

(b)

Figure 2. Optical microscopic images for Polymethyl methacryrate (PMMA) specimens (a) before and (b) after selling process.

These specimens were immersed in liquid cultures with bacteria. Figure 3 shows the surfaces of glass substrates as references after biofilm formation by E. coli and S. epidermidis, respectively. It was not easy for biofilms to form on glass specimens. However, biofilms were observed in some parts of the substrates. The scattered individual bacteria could be observed. However, some aggregates composed of bacteria were also observed. The latter should be biofilms. The light points (in the photos) are reflections of laser beams on the specimens. In both cases of bacteria (Figure 3a for the case of E. coli and Figure $3 \mathrm{~b}$ for the case of S. epidermidis), the photos show biofilm formations on glass specimens. 


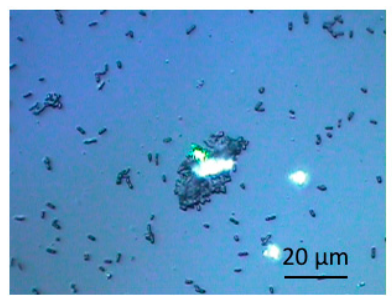

(a)

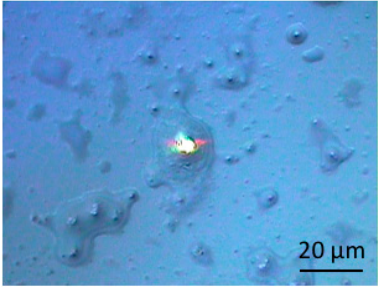

(b)

Figure 3. Optical microscopic images for glass substrates after biofilm formation: (a) E. coli and (b) S. epidermidis.

Figure 4 shows the optical microscopic images for surfaces of DEMM polymer brush specimens after biofilm formations by $E$. coli and S. epidermidis, respectively. Being compared with the results shown in Figures 1 and 2, surfaces of DEMM polymer brush specimens appear to be filled with contaminants. The results clearly show that biofilms were formed on the entire surfaces of the specimens.

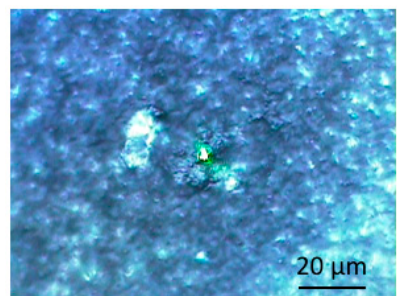

(a)

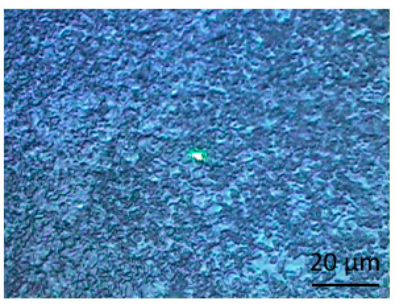

(b)

Figure 4. Optical microscopic images for DEMM polymer brush specimens after biofilm formation: (a) E. coli and (b) S. epidermidis.

Figure 5 shows the optical microscopic images for the surfaces of PMMA polymer brush specimens after biofilm formations (by these same bacteria). Figure 5a, corresponds to the result of E. coli, while Figure $5 \mathrm{~b}$ refers to that of $S$. epidermidis. In both cases, biofilms can be observed in the same way. However, they seem to exist locally. There were still some places where no biofilms were observed. Even brushes could be observed in the backgrounds. The brushes in Figure $5 \mathrm{~b}$ appear swollen through the biofilm formation process. These results show that it is more difficult for the biofilms to form on PMMA polymer brush specimens than on those of DEMM.

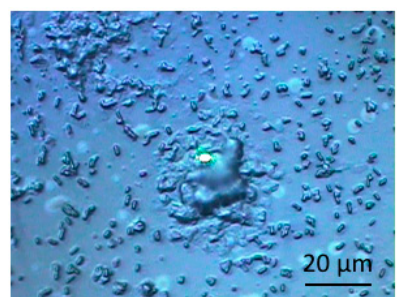

(a)

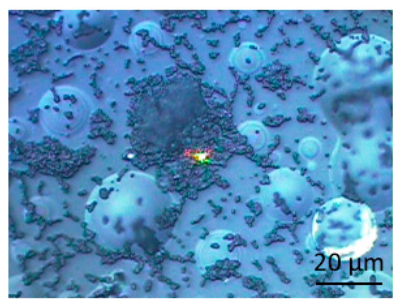

(b)

Figure 5. Optical microscopic images for PMMA polymer brush specimens after biofilm formation: (a) E. coli and (b) S. epidermidis.

\subsection{Raman Scpetroscopy}

All of the specimens were subjected to Raman spectroscopy and the results were analyzed to confirm the presence of biofilm by "finger print method" (Identification by comparing the data with those in the previous papers [71-81]). For each case, the same measurements were repeated three times for three specimens and the three results for each case were overlapped in the Raman shift 
charts basically, except for some problematic exceptional cases. Even though the measurement points on each specimen were chosen randomly, bacteria assembled and EPS was confirmed by the optical microscopy for all of those measurement points.

Before biofilm formation, the DEMM coating and PMMA coating did not show any characteristic Raman peaks. In both cases, Raman displayed small peaks of glass substrate that were observed at 1080 and $560 \mathrm{~cm}^{-1}$. On the contrary, many characteristic peaks appeared for the specimens after the biofilm formation processes. Figure 6 shows the results for glass substrates. Figure 6 a corresponds to the results of E. coli. In this case, unfortunately, the third specimen gave no robust data due to a signal failure. The first specimen showed a slightly different result from the second. From the two results, we could judge that biofilms were formed on glass substrates, since most of them could be attributed to polymers derived from biofilms or bacteria. The peak around 570 and $800 \mathrm{~cm}^{-1}$ could be attributed to polysaccharides or lipids [71,72]. The peak around $1100 \mathrm{~cm}^{-1}$ could be assigned also to that of polysaccharides or lipids [71,73]. Also, the peak around $2800 \mathrm{~cm}^{-1}$ could be assigned to polysaccharides [74] and lipids [75]. Figure $6 \mathrm{~b}$ shows the results of S. epidermidis for glass specimens. The peak relating to nucleic acids around $2400 \mathrm{~cm}^{-1}$ [73] was observed in the case of S. epidermidis. The peak of polysaccharides and/or lipids at $2800 \mathrm{~cm}^{-1}$ was observed clearly. Lipid's peak was observed also at $1400 \mathrm{~cm}^{-1}$ for the first specimen [75]. The peak for polysaccharides/lipids at $1100 \mathrm{~cm}^{-1}$ [71,73] was also observed. Two peaks between 500 and $800 \mathrm{~cm}^{-1}$ would be related to polysaccharides/lipids [71,72].

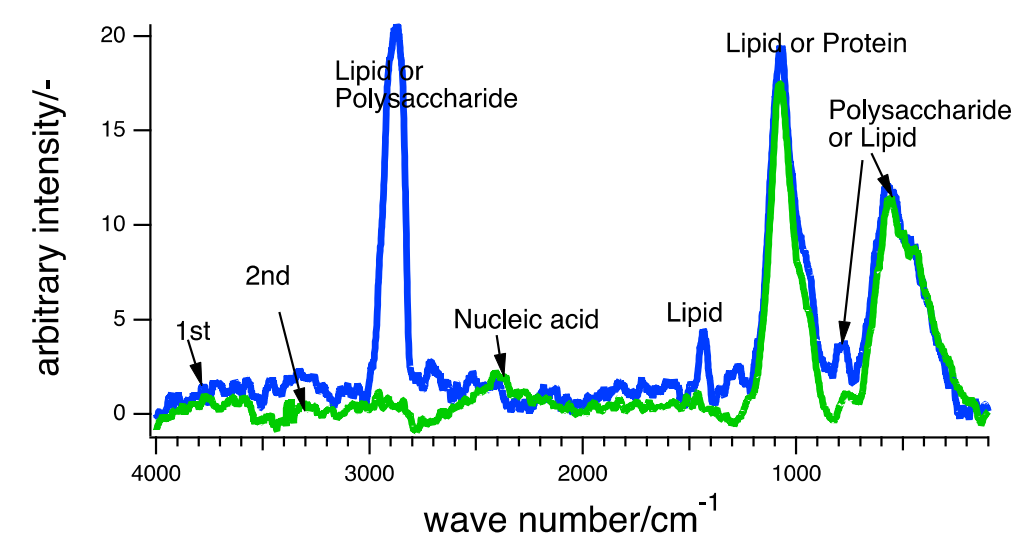

(a)

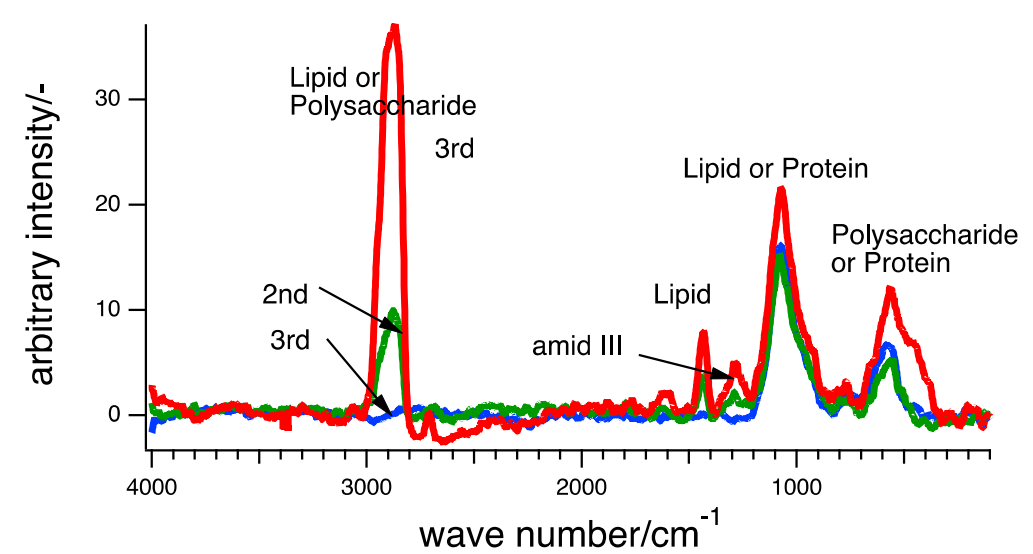

(b)

Figure 6. Raman peaks on glass substrates after biofilm formation: (a) E. coli and (b) S. epidermidis.

Figure 7 shows the results for DEMM polymer brush specimens. Figure 7 a shows the results in the case of E. coli. All of the specimens show similar tendencies for Raman peaks, except for the 
broad one around $2000 \mathrm{~cm}^{-1}$ (peaks for stretching or vibration of triple bonds between carbon-carbon or carbon-nitrogen) [76]. However, the peak was not observed for the third specimen. For other peaks, most of them were overlapped, even though the intensities were different from each other. The peak around $2800 \mathrm{~cm}^{-1}$ could be attributed to those for polysaccharides and/or lipids [74,75]. The peak around $1400 \mathrm{~cm}^{-1}$ was considered that for lipids [74]. The small peak at $1300 \mathrm{~cm}^{-1}$ is highly likely that for amid III (protein) [72], while that at $1100 \mathrm{~cm}^{-1}$ could be assigned to that for lipids or proteins [71,73]. The broad peak around $2000 \mathrm{~cm}^{-1}$ corresponding of triple bonds between carbon atoms or carbon-nitrogen has been still undecidable. It suggests nitrile compounds or alkyne molecules would exist. Both might be formed through some components derived from biofilms, since the broad peaks were sometimes found in the past by us [79]. However, in this case, we used acetonitrile to swell the brush coating. It was highly likely that the chemical was remained at the upper side of coating. Figure $7 \mathrm{~b}$ shows the results in the case of S. epidermidis. In this case, peaks for three specimens were almost overlapped, even though the strengths were different for each of them. The broad peak was also observed around $2000 \mathrm{~cm}^{-1}$ [76]. The peak around $2800 \mathrm{~cm}^{-1}$ could be attributed to that for lipids/polysaccharides [74,75], while lipids or proteins peaks were observed at $1100 \mathrm{~cm}^{-1}$ [75].

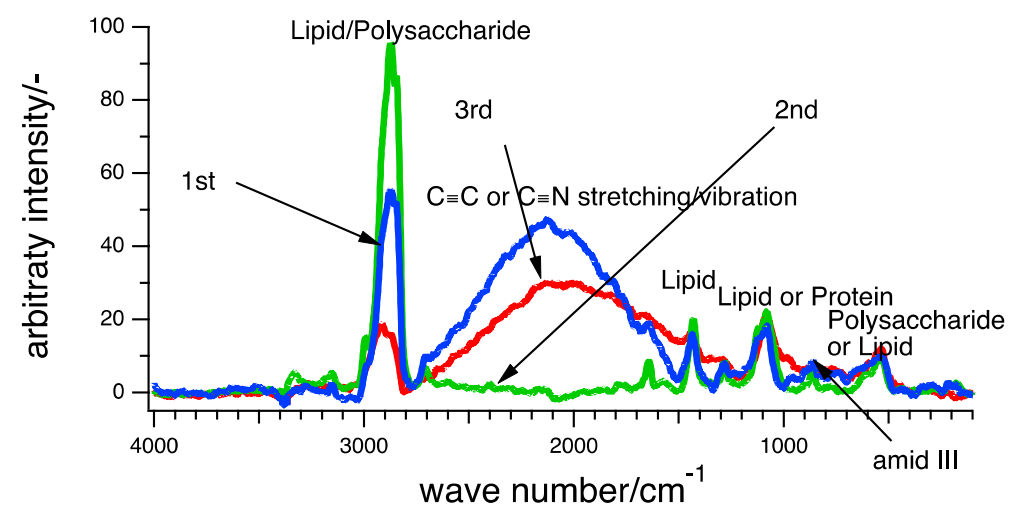

(a)

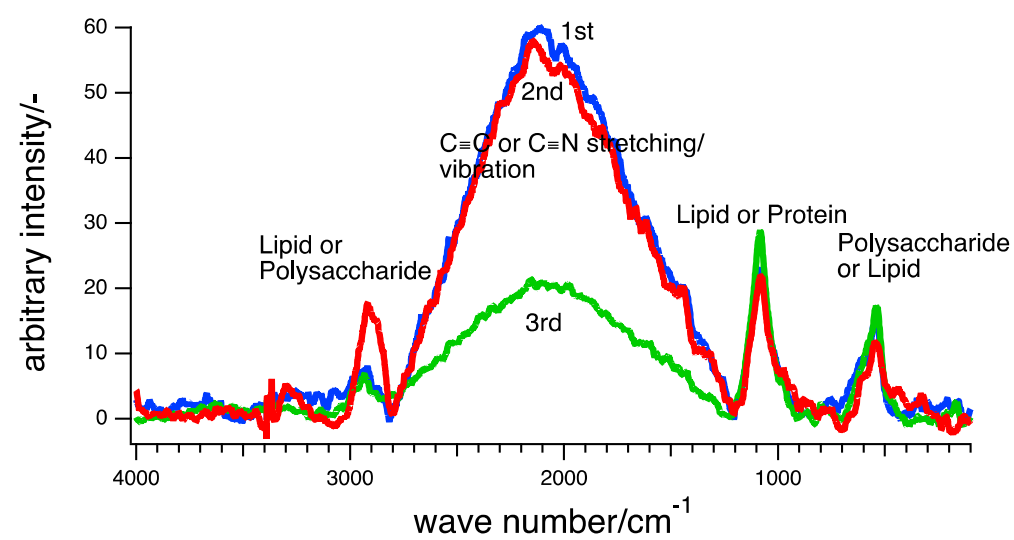

(b)

Figure 7. Raman peaks on DEMM polymer brush specimens after biofilm formation: (a) E. coli and (b) S. epidermidis.

Figure 8 shows the results for PMMA specimens. Also in these cases, most of the peaks were overlapped in both cases. In the case of E. coli (Figure 8a), the second specimens could not be shown due to the unintentional signal failures. In the case of $S$. epidermidis, more complicated peaks (than those in other cases) appeared, as shown in Figure $8 \mathrm{a}, \mathrm{b}$. Peaks around $2800 \mathrm{~cm}^{-1}$ could be attributed to either of polysaccharides [74] (at higher wave number) or lipids [75] (at lower wave number). Both peaks were almost overlapped around $2800 \mathrm{~cm}^{-1}$. The peak around $1600 \mathrm{~cm}^{-1}$ was considered the 
one for polysaccharides [74]. The peak at $1400 \mathrm{~cm}^{-1}$ could be assigned to that for lipids [75]. Three peaks seen from 1100 to $1400 \mathrm{~cm}^{-1}$ belong to lipids or proteins [72,79]. We presume that the new peak just over $3000 \mathrm{~cm}^{-1}$ would belong to lipid [79] (However, we could not deny the possibility of nucleic acids [73]). Other new ones at $1000 \mathrm{~cm}^{-1}$ would be assigned to amino acid (phenylalanine) [71]. Small peaks from 550 to $800 \mathrm{~cm}^{-1}$ could usually be assigned to polysaccharides or lipids [71,72]. Therefore, we presume that biofilms formed on the specimen (particularly PMMA) and the sticky surface as a result of having the components of culture media incorporated into them. All of these Raman spectroscopic analyses suggest that biofilms formed on specimens' surfaces. However, they indicate that biofilms were more difficult to form on PMMA than on DEMM polymer brush coated specimens. This tendency was also supported by the results of microscopic observations. Particularly, the tendency was very remarkable for nucleic acids derived from biofilms.

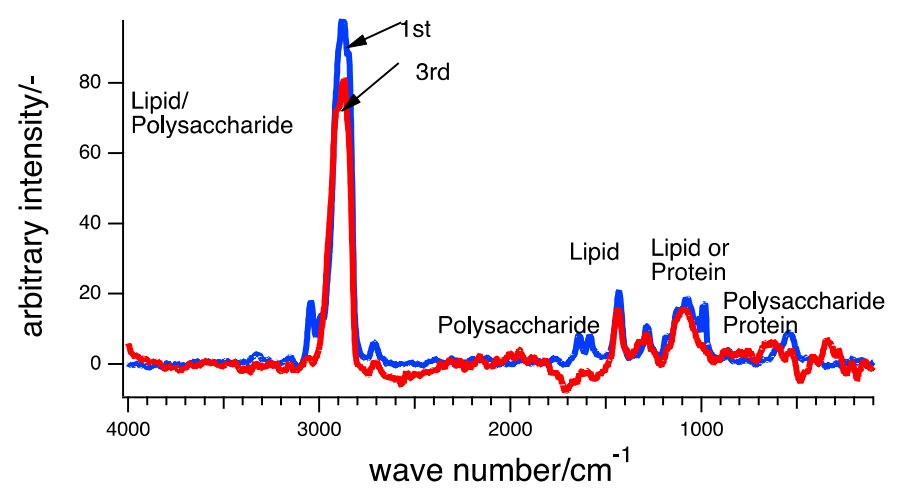

(a)

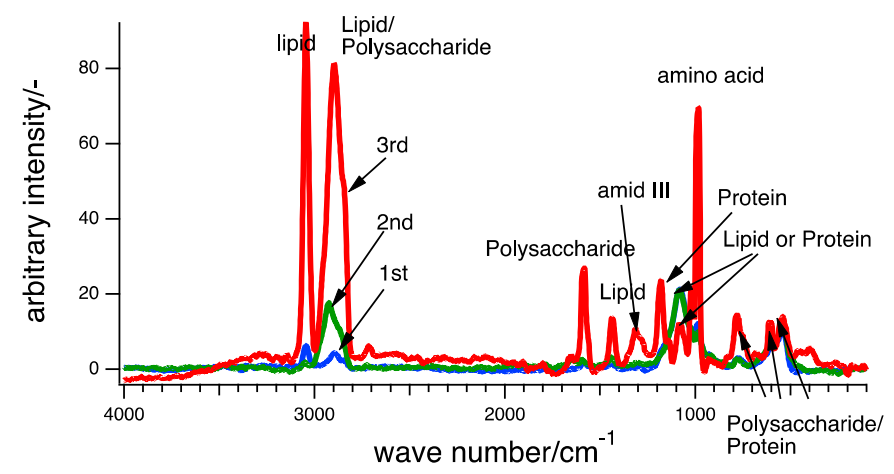

(b)

Figure 8. Raman peaks on PMMA polymer brush specimens after biofilm formation: (a) E. coli and (b) S. epidermidis.

\section{Discussion}

In these experiments, we vividly observed the biofilms formed on DEMM brush coated specimens. However, the contaminants derived from biofilms could be washed away easily by rinsing with water. From this viewpoint, the ionic liquid type polymer brush like DEMM would be convenient and favorable. This is because it could easily attract biofilms and the related contaminants on the materials' surfaces.

Figure 9 schematically illustrates the mechanism of antifouling for a polymer brush coating. In water and some other liquids, the polymer brush would contain water droplets between brushes (Figure 9a,b). Due to the static electrical force or mechanical one caused by geographical configurations, bacteria could get trapped and result in the formation of biofilm. However, the hydrophobic parts of the biofilms act repulsively against water drops trapped between brushes. Then they could be washed away easily as a whole (Figure $9 b, c)$. In addition, brushes would be swollen in the aqueous solution 
further. The swollen effect would be added to the buoyancy and repulsion forces. Thus, biofilms could be removed. However, being compared with PMMA polymer brush coated specimens, why would DEMM polymer brush coating specimens attract bacteria-biofilms-contaminants so much?

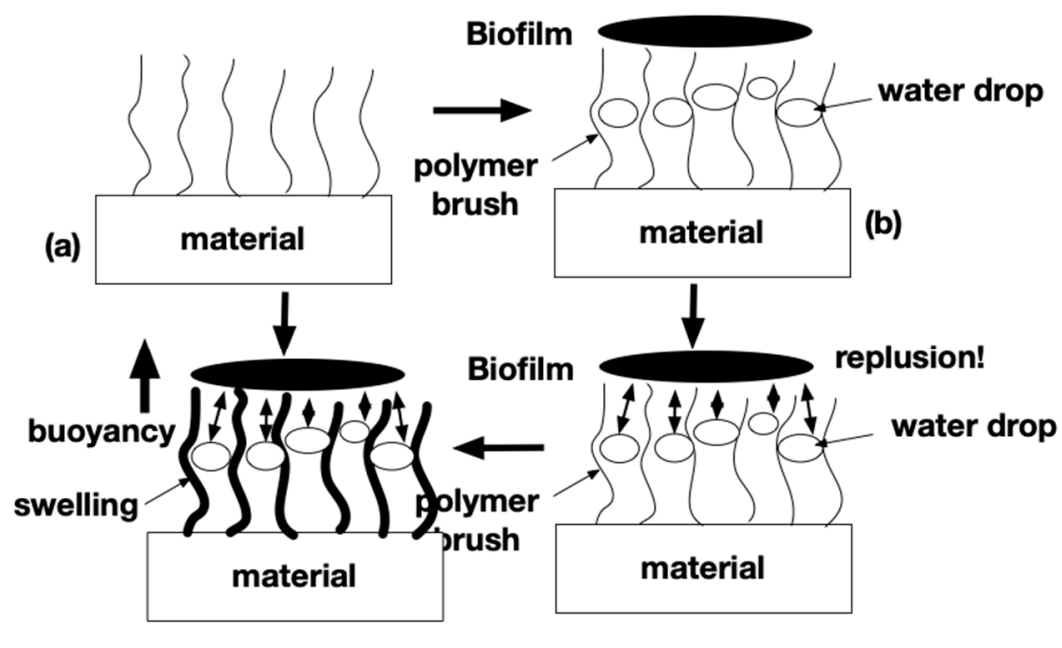

(d)

(c)

Figure 9. The mechanism of antifouling for polymer brush coating. (a) Polymer brush coating before immersion into a liquid solution. (b) Water drops are trapped in polymer brush coating, while biofilms formed by bacterial activities are attached to the top of polymer brush. (c) Repulsion forces are produced between water drops and hydrophobic parts of biofilms. (d) Water drops push biofilms up with its buoyancy and swelling action of polymer brush.

The most likely answer is due to the polar characteristics and the differences between the two types of polymer brush coated specimens. The surface of a PMMA brush coated specimen is generally neutral, while that of a DEMM brush coated specimen is polarized. Therefore, a DEMM polymer brush would tend to attract biofilms more.

From the viewpoint of merits as the ionic liquid, we could conclude that ionic liquid type polymer brush coating could attract biofilms and contaminants as a result much more in the vicinity of surfaces. Then they could be washed away by water washing [57]. The characteristic would lead to various applications such as automobiles and medical instruments. In addition, according to the practical purposes, some persons may want to remove any contaminants from the beginning. The attachment and attraction of bacteria and the following biofilm formation seem to depend on the polar characters [82]. Fortunately, the ionic liquid could arrange the polar characteristics easily. Therefore, the appropriate combination of ionic liquids and polymer brush production processes might lead to some changes of anti-biofouling effect and properties in the future, if they would be required and needed. When we come to think about those characteristics (about the application of ionic liquids to a polymer brush coating), this type of polymer brush would have a promising future as an advanced coating and material.

\section{Conclusions}

DEMM polymer brush coating as a liquid ionic polymer brush was investigated from the viewpoint of its biofilm formation and antifouling effect. It was also compared with the results for the PMMA polymer brush coating. Our results are demonstrated.

- Optical microscopic observations and Raman spectroscopic analyses confirmed that all specimens could form biofilms on their surfaces (more or less).

- DEMM polymer brush coating tended to form biofilms on the surfaces more than PMMA polymer brush specimens. 
- Nucleic acids in biofilms could be confirmed more often for DEMM polymer brush coating specimens.

- These results suggest that the polar characteristics would play an important role in the antifouling effect related to biofilm formation.

- Ionic liquid type polymer brush coating would be beneficial to remove contaminants as a whole, due to the trapping and removing capabilities.

- Ionic liquid type polymer brush coating may change their polar characteristics leading to the antifouling effect of materials' surfaces in the future.

Author Contributions: Planning, experiments for biofilms, writing drafts, data curation, H.K. and A.O. (Atsuya Oizumi); Producing polymer brush coating specimens, discussion, advice, T.S., T.K. (Toshio Kamijo) and S.H.; Writing-review \& editing, proof-reading, discussion, D.M.B.; Discussion and advice for biofilm formation and evaluation, N.H., A.O. (Akiko Ogawa), T.K. (Takeshi Kogo), D.K. and K.S., Discussion and advice for ionic liquids, K.T.; Discussion and advice from the viewpoint of application, S.-H.L. and M.-H.L.

Funding: This research was funded by JSPS KAKENHI (Grants-in-Aid for Scientific Research from Japan Society for the Promotion of Science) Grant Number 17K06826. This study was funded also by Mitsubishi Electric Corporation and the Society of Industrial Technology for Antimicrobial Articles (SIAA).

Acknowledgments: The current investigation was carried out under the project entitled Network Formation Project, 2017 by the headquarters of the National Institute of Technology (Kosen) financially (Network Formation Project, 2017). We would like to thank them for their constant encouragement. We very highly appreciate Mitsubishi Electric Corporation and its research center of advanced technology for their useful advice and financial support. Also we would like to thank the Society of Industrial Technology for Antimicrobial Articles (SIAA) as well as the Japan Food Research Laboratory (JFRL).

Conflicts of Interest: The authors declare no conflict of interest. The funders had no role in the design of the study; in the collection, analyses, or interpretation of data; in the writing of the manuscript, or in the decision to publish the results.

\section{References}

1. Fusetani, N. Biofouling and antifouling. Nat. Prod. Rep. 2004, 21, 94-104. [CrossRef] [PubMed]

2. Yebra, D.M.; Kiil, S.; Dam-Johansen, K. Antifouling technology-Past, present and future steps towards efficient and environmentally friendly antifouling coatings. Prog. Org. Coat. 2004, 50, 75-104. [CrossRef]

3. Chambers, L.D.; Stokes, K.R.; Walsh, F.C.; Wood, R.J. Modern approaches to marine antifouling coatings. Surf. Coat. Technol. 2006, 201, 3642-3652. [CrossRef]

4. Banerjee, I.; Pangule, R.C.; Kane, R.S. Antifouling coatings: Recent developments in the design of surfaces that prevent fouling by proteins, bacteria, and marine organisms. Adv. Mater. 2011, 23, 690-718. [CrossRef] [PubMed]

5. Lejars, M.; Margaillan, A.; Bressy, C. Fouling release coatings: A nontoxic alternative to biocidal antifouling coatings. Chem. Rev. 2012, 112, 4347-4390. [CrossRef] [PubMed]

6. Swain, G.W.; Schultz, M.P. The testing and evaluation of non-toxic antifouling coatings. Biofouling 1996, 10, 187-197. [CrossRef] [PubMed]

7. Brady, R.F., Jr. A fracture mechanical analysis of fouling release from nontoxic antifouling coatings. Prog. Org. Coat. 2001, 43, 188-192. [CrossRef]

8. Gudipati, C.S.; Greenlief, C.M.; Johnson, J.A.; Prayongpan, P.; Wooley, K.L. Hyperbranched fluoropolymer and linear poly(ethylene glycol) based amphiphilic crosslinked networks as efficient antifouling coatings: An insight into the surface compositions, topographies, and morphologies. J. Polym. Sci. Part A Polym. Chem. 2004, 42, 6193-6208. [CrossRef]

9. Hellio, C.; Yebra, D. Advances in Marine Antifouling Coatings and Technologies, 1st ed.; Woodhead Publishing: Cambridge, UK, 2009.

10. Casse, F.; Swain, G.W. The development of microfouling on four commercial antifouling coatings under static and dynamic immersion. Int. Biodeterior. Biodegrad. 2006, 57, 179-185. [CrossRef]

11. Mittal, K.L. Surface contamination: An overview. In Surface Contamination-Genesis, Detection, and Control, 1st ed.; Springer: Boston, MA, USA, 1979; pp. 3-45. 
12. Dobretsov, S.; Thomason, J.; Williams, D.N. Biofouling Methods, 1st ed.; Wiley-Blackwell: Hoboken, NJ, USA, 2014.

13. Dürr, S.; Thomason, J.C. Biofouling, 1st ed.; Wiley-Blackwell: Hoboken, NJ, USA, 2009.

14. Corpe, W.A. Microfouling: The role of primary film forming marine bacteria. In Proceedings of the 3rd International Congress of Marine Corrosion and Fouling, Gaithersburg, MD, USA, 2-6 October 1972; Northwestern University Press: Evanston, IL, USA, 1973.

15. Claudi, R.; Mackie, G.L. Practical Manual for the Monitoring and Control; Lewis Publishers: Boca Raton, FL, USA, 1994.

16. Kanematsu, H.; Barry, D.M. Biofilm and Materials Science; Springer: New York, NY, USA, 2015.

17. Lewandowski, Z.; Beyenal, H. Fundamentals of Biofilm Research, 2nd ed.; CRC Press: Boca Raton, FL, USA, $2014 ;$ p. 642.

18. Kalmbach, S.; Manz, W.; Szewzyk, U. Biofilms—Investigative Methods E Applications; CRC Press: Boca Raton, FL, USA, 2000.

19. Flemming, H.C.; Murthy, S.P.; Venkatesan, R.; Cooksey, K. Marine and Industrial Biofouling; Springer: Berlin, Germany, 2009.

20. Kanematsu, H.; Ikigai, H.; Campbell, S.; Beech, I. Sn-Ag alloy plating films mitigating biofilm formation. In Proceedings of the National Association for Surface Finishing Annual Technical Conference 2009, Louisville, KY, USA, 16-17 June 2009; Curran Associates, Inc.: Red Hook, NY, USA, 2009; pp. 406-415.

21. Kanematsu, H.; Ikigai, H.; Yoshitake, M. Evaluation of various metallic coatings on steel to mitigate biofilm formation. Int. J. Mol. Sci. 2009, 10, 559-571. [CrossRef] [PubMed]

22. Kanematsu, H.; Ikegai, H.; Kuroda, D. Biofilm and metallic materials. Rust Prev. Control Jpn. 2011, 55, 369-377.

23. Kanematsu, H.; Kougo, T.; Kuroda, D.; Itoh, H.; Noorani, R. Prevention coating against biofilm formation. In Proceedings of the Sur/Fin Asia-Pacific 2012, Singapore, 4-7 December 2012; pp. 52-56.

24. Kanematsu, H.; Kuroda, D.; Itoh, H.; Ikigai, H. Biofilm formation of a closed loop system and its visualization. CAMP-ISIJ 2012, 25, 753-754.

25. Kanematsu, H.; Kuroda, D.; Itoh, H.; Kobayashi, T.; Noorani, R.; Yamamoto, M.; Tsukuda, I. Chemical surface treatment for prevention against biofilm formation. In Proceedings of the Sur/Fin Asia-Pacific 2012, Singapore, 4-7 December 2012; pp. 57-62.

26. Kanematsu, H.; Kuroda, D.; Koya, S.; Itoh, H. Development of production process on labo scale for biofilm formation by immersion into closed circulation water system. J. Surf. Finish. Soc. Jpn. 2012, 63, 459-461. [CrossRef]

27. Kanematsu, H.; Miura, Y.; Itoh, H.; Ikigai, H.; Tanaka, M. Condensation behavior of silicon into biofilm formed by germs in ambient atmosphere in a laboratory and its observation. CAMP-ISIJ 2012, 25, 810-811. (In Japanese)

28. Kanematsu, H.; Hihara, T.; Ishihara, T.; Imura, K.; Kogo, T. Evaluation for corrosion resistance of nano-cluster layer and biofilm formation. Int. J. Eng. Sci. Res. Technol. 2013, 2, 2424-2432.

29. Kanematsu, H.; Hirai, N.; Miura, Y.; Itoh, H.; Kuroda, D.; Umeki, S. Biofilm leading to corrosion on material surface and the moderation by alternative electro-magnetic field. In Proceedings of the Materials Science and Technology Conference and Exhibition 2013 (MS\&T 2013), Monatreal, QC, Canada, 27-31 October 2013; pp. 2761-2767.

30. Kanematsu, H.; Hirai, N.; Miura, Y.; Itoh, H.; Masuda, T.; Kuroda, D. Evaluation technique for biofilm formed on biomaterials. In Proceedings of the 4th International Symposium on Advanced Materials Development and Integration of Novel Structured Metallic and Inorganic Materials, Nagoya, Japan, 13-15 December 2013; Nagoya University: Nagoya, Japan, 2013.

31. Kanematsu, H.; Hirai, N.; Miura, Y.; Tanaka, M.; Kogo, T.; Itoh, H. Various metals from water by biofilm from an ambient germs in a reaction container. In Proceedings of the Materials Science and Technology Conference and Exhibition 2013 (MS\&T 2013), Montreal, QC, Canada, 27-31 October 2013; pp. 2154-2161.

32. Kanematsu, H.; Itoh, H.; Miura, Y.; Masuda, T.; Kuroda, D.; Hirai, N.; Barry, D.M.; McGrath, P.B. Biofilm formation on polymer materials by a laboratory acceleration reactor. In Proceedings of the 4th International Symposium on Advanced Materials Development and Integration of Novel Structured Metallic and Inorganic Materials, Nagoya, Japan, 13-15 December 2013; Nagoya University: Nagoya, Japan, 2013. 
33. Kougo, T.; Yamamoto, Y.; Naiki, A.; Ogino, Y.; Kanzaki, T.; Kanematsu, H.; Ikigai, H.; Itoh, H. Proposal for Evaluation to Biofilm Formation on Metal Oxides in Atmospheric Exposure Type Circulation Water System. Mem. Suzuka Natl. Coll. Technol. 2013,46, 81-84.

34. Kanematsu, H.; Kogo, T.; Itoh, H.; Wada, N.; Yoshitake, M. Fogged glass by biofilm formation and its evaluation. In Proceedings of the Materials Science and Technology Conference and Exhibition 2013 (MS\&T 2013), Montreal, QC, Canada, 27-31 October 2013; pp. 2427-2433.

35. Kanematsu, H.; Kogo, T.; Kuroda, D.; Itoh, H.; Kirihara, S. Biofilm formation and evaluation for spray coated metal films on laboratory scale. In Proceedings of the Thermal Spray 2013-Innovative Coating Solutions for the Global Economy, Busan, Korea, 13-15 May 2013; pp. 520-525.

36. Kanematsu, H.; Kougo, T.; Kuroda, D.; Ogino, Y.; Yamamoto, Y. Biofilm formation derived from ambient air and the characteristics of apparatus. J. Phys. Conf. Ser. 2013, 433, 012031. [CrossRef]

37. Kanematsu, H.; Okura, Y.; Hirai, N.; Miura, Y.; Itoh, H.; Tanaka, M. Condensation of some metal elements in biofilm. CAMP-ISIJ 2013, 26, 417. (In Japanese)

38. Ikegai, H.; Kobayashi, M.; Ken-ichi Iimura; Hosokawa, A.; Uesugi, K.; Korda, D.; Kanematsu, H.; Toda, H. X-ray computed tomography for observing microbiologically influenced corrosion of carbon steel caused by Pseudomonas aeruginosa biofilm sig synchrotron radiation in Spring-8. Bact. Adherence Biofilm 2014, 28, 67-70. (In Japanese)

39. Kanematsu, H.; Kogo, T.; Noda, M.; Hirai, N.; Ogawa, A.; Miura, Y.; Itoh, H.; Yoshitake, M. Composite coating to control biofilm formation and MIC. In Proceedings of the 17th International Congress on Marine Corrosion and Fouling (ICMCF), National University of Singapore, Singapore, 6-10 July 2014; p. 101.

40. Kanematsu, H.; Kogo, T.; Sano, K.; Noda, M.; Wada, N.; Yoshitake, M. Nano-composite coating on glasses for biofilm control. J. Mater. Sci. Surf. Eng. 2014, 1, 58-63.

41. Kanematsu, H.; Noda, M.; Hirai, N.; Ogawa, A.; Kogo, T.; Miura, Y.; Ito, H. A trial for MIC study using a circulation-type laboratory biofilm reactor. In Proceedings of the 17th International Congress on Marine Corrosion and Fouling (ICMCF), National University of Singapore, Singapore, 6-10 July 2014; p. 75.

42. Kanematsu, H.; Tanaka, M. Biofilm analyses and their importance in materials science and engineering. Bunseki Kagaku 2014, 63, 569-580. (In Japanese) [CrossRef]

43. Ikegai, H.; Hirai, N.; Kobayashi, M.; Toda, H.; Moroboshi, T.; Ikeda, T.; Ikeda, S.; Uesugi, K.; Kuroda, D.; Kanematsu, H. Microbiologically influenced corrosion to carbon steel and biomineralization caused by pseudomonas aeruginosa biofilm. Bact. Adherence Biofilm 2015, 29, 93-96. (In Japanese)

44. Kanematsu, H.; Sasaki, S.; Miura, Y.; Kogo, T.; Sano, K.; Wada, N.; Yoshitake, M.; Tanaka, T. Composite coating to control biofilm formation and effect of alternate electro-magnetic field. Mater. Technol. 2015, 30, 21-26. [CrossRef]

45. Ogawa, A.; Noda, M.; Kanematsu, H.; Sano, K. Application of bacterial16S rRNAgene analysis to a comparison of the degree of biofilm formation on the surface of metal coated glasses. Mater. Technol. 2015, 30, 61-65. [CrossRef]

46. Kanematsu, H.; Kudara, H.; Kanesaki, S.; Kogo, T.; Ikegai, H.; Ogawa, A.; Hirai, N. Application of a loop-type laboratory biofilm reactor to the evaluation of biofilm for some metallic materials and polymers such as urinary stents and catheters. Materials 2016, 9, 824-834. [CrossRef] [PubMed]

47. Kanematsu, H.; Umeki, S.; Hirai, N.; Miura, Y.; Wada, N.; Kogo, T.; Tohji, K.; Otani, H.; Okita, K.; Ono, T. Verification of effect of alternative electromagnetic treatment on control of biofilm and scale formation by a new laboratory biofilm reactor. Ceram. Trans. 2016, 259, 199-212. [CrossRef]

48. Kanematsu, H.; Umeki, S.; Ogawa, A.; Hirai, N.; Kogo, T.; Tohji, K. The cleaning effect on metallic materials under a weak alsternating electromagnetic field and biofilm. In Proceedings of the Ninth Pacific Rim International Conference on Advanced Materials and Processing (PRICM9), Kyoto, Japan, 1 August 2016; pp. 1-4.

49. Sano, K.; Kanematsu, H.; Kogo, T.; Hirai, N.; Tanaka, T. Corrosion and biofilm for a composite coated iron observed by FTIR-ATR and Raman spectroscopy. Trans. Inst. Mater. Finish. 2016, 94, 139-145. [CrossRef]

50. Kanematsu, H. Evaluation and countermeasure for biofilms on inorganic surface. In Biofilm Structure and Formation for Biocontrol and Countermeasure of Biofilms and Its Growth; Matsumura, Y., Ed.; CMC Publisher: Osaka, Japan, 2017; pp. 162-189.

51. Kanematsu, H.; Barry, D.M.; Ikegai, H.; Yoshitake, M.; Mizunoe, Y. Biofilm evaluation methods outside body to inside-Problem presentations for the future. Med. Res. Arch. 2017, 5, 1469. 
52. Kanematsu, H.; Saito, T.; Barry, D.M.; Hirai, N.; Kogo, T.; Ogawa, A.; Tsunashima, K. Effects of ionic liquids on biofilm formation in a loop-type laboratory biofilm reactor. ECS Trans. 2017, 80, 1147-1155. [CrossRef]

53. Kanematsu, H.; Satoh, M.; Shindo, K.; Barry, D.M.; Hirai, N.; Ogawa, A.; Kogo, T.; Utsumi, Y.; Yamaguchi, A.; Ikegai, H.; et al. Biofilm formation behaviors on graphene by E. coli and S. epidermidis. ECS Trans. 2017, 80, 1167-1175. [CrossRef]

54. Sano, K.; Masuda, T.; Kanematsu, H.; Yokoyama, S.; Hirai, N.; Ogawa, A.; Kougo, T.; Yamazaki, K.; Tanaka, T. Biofouling on mortar mixed with steel slags in a laboratory biofilm reactor. In Proceedings of the Irago Conference 2016, Irago, Aichi, Japan, 1-2 November 2016; p. 02004.

55. Kanematsu, H. A new international standard for testing antibacterial effects. Adv. Mater. Process. 2017, 175, 26-29.

56. Kanematsu, H.; Maeda, S.; Barry, D.M.; Umeki, S.; Tohji, K.; Hirai, N.; Ogawa, A.; Kogo, T.; Ikegai, H.; Mizunoe, Y. Effects of elastic waves at several frequencies on biofilm formation in circulating laboratory biofilm reactors. Ceram. Trans. 2018, 265, 43-51.

57. Kanematsu, H.; Oizumi, A.; Sato, T.; Kamijo, T.; Honma, S.; Barry, D.M.; Hirai, N.; Ogawa, A.; Kogo, T.; Kuroda, D.; et al. Polymer brush made by ionic liquids and the inhibition effects for biofilm formation. ECS Trans. 2018, 85, 1089-1095. [CrossRef]

58. Kanematsu, H.; Shindo, K.; Barry, D.M.; Hirai, N.; Ogawa, A.; Kuroda, D.; Kogo, T.; Sano, K.; Ikegai, H.; Mizunoe, Y. Electrochemical responses of graphene with biofilm formation on various metallic substrates by using laboratory biofilm reactors. ECS Trans. 2018, 85, 491-498. [CrossRef]

59. Milner, S.T.; Witten, T.A.; Cates, M.E. Theory of the grafted polymer brush. Macromolecules 1988, 21, 2610-2619. [CrossRef]

60. Milner, S.T. Polymer brushes. Science 1991, 251, 905-914. [CrossRef] [PubMed]

61. Zhou, F. Antifouling Surfaces and Materials_From Land to Marine Environment, 1st ed.; Springer: Berlin/Heidelberg, Germany, 2015.

62. Sato, T.; Morinaga, T.; Marukane, S.; Narutomi, T.; Igarashi, T.; Kawano, Y.; Ohno, K.; Fukuda, T.; Tsuji, Y. Novel solid-state polymer electrolyte of colloidal crystal decorated with ionic-liquid polymer brush. Adv. Mater. 2011, 23, 4868-4872. [CrossRef] [PubMed]

63. Arafune, H.; Kamijo, T.; Morinaga, T.; Honma, S.; Sato, T.; Tsuji, Y. A robust lubrication system using an ionic liquid polymer brush. Adv. Mater. Interfaces 2015, 2, 1500187. [CrossRef]

64. Morinaga, T.; Honma, S.; Ishizuka, T.; Kamijo, T.; Sato, T.; Tsuji, Y. Synthesis of monodisperse silica particles grafted with concentrated ionic liquid-type polymer brushes by surface-initiated atom transfer radical polymerization for use as a solid state polymer electrolyte. Polymers 2016, 8, 146-159. [CrossRef]

65. Hideyuiki, K.; Barry, D.M.; Ikegai, H.; Yoshitake, M.; Mizunoe, Y. Nanofibers and biofilm in materials science. In Handbook of Nanofibers. Vol. I: Fundamental Aspects, Experimental Setup, Synthesis, Properties and Physicochemical Characterization; Barhoum, A., Bechelany, M., HamdyMakhlouf, A.S., Eds.; Springer Nature Switzerland AG: Basel, Switzerland, 2018; pp. 1-21.

66. Yamamoto, S.; Ejaz, M.; Tsujii, Y.; Fukuda, T. Surface interaction forces of well-defined, high-density polymer brushes studies by atomic force microscopy. 2. Effect of graft density. Macromolecules 2000, 33, 5608-5612. [CrossRef]

67. Tsujii, Y.; Ohno, K.; Yamamoto, S.; Goto, A.; Fukuda, T. Structure and properties of high-density polymer brushes prepared by surface-initiated living radical polymerization. In Surface-Initiated Polymerization; Jordan, R., Ed.; Springer Nature: Heidelberg, Germany, 2006; pp. 1-45.

68. Nomura, A.; Ohno, K.; Fukuda, T.; Sato, T.; Tsujii, Y. Lubrication mechanisms of concentrated polymer brushes in solvents: Effect of solvent viscosity. Polym. Chem. 2012, 3, 148-153. [CrossRef]

69. Zhu, B.; Edmondson, S. ARGET ATRP: Procedure for PMMA polymer brush growth. Available online: https:www.sigmaaldrich.com/technical-documents/articles/crp-guide/arget-atrp-procedure-for-pmmapolymer-brush-growth.html (accessed on 7 November 2018).

70. Zhu, B.; Edmondson, S. Polydopamine-melanin initiators for surface-initiated ATRP. Polymer 2011, 52, 2141-2149. [CrossRef]

71. Chao, Y.; Zhang, T. Surface-enhanced Raman scattering (SERS) revealing chemical variation during biofilm formation: From initial attachment to mature biofilm. Anal. Bioanal. Chem. 2012, 404, 1465-1475. [CrossRef] [PubMed] 
72. Lakin, P. General Outline and Strategies for IR and Raman Spectral Interpretation. In Infrared and Raman Spectroscopy-Principles and Spectral Interpretation; Elsevier: Burlington, MA, USA, 2011; pp. 117-133.

73. George, J.; Thomas, J. Raman spectroscopy of protein and nucleic acid assmeblies. Annu. Rev. Biophys. Biomol. Struct. 1999, 28, 1-27.

74. Yuen, S.N.; Choi, S.M.; Phillips, D.L.; Ma, C.Y. Raman and FTIR spectroscopic study of carboxymethylated non-starch polysaccharides. Food Chem. 2009, 114, 1091-1098. [CrossRef]

75. Czamara, K.; Majzner, K.; Pacia, M.Z.; Kochan, K.; Kaczor, A.; Baranska, M. Raman spectroscopy of lipids: A review. J. Raman Spectrosc. 2015, 46, 4-20. [CrossRef]

76. Lakin, P. IR and Raman spectra-structure correlations: Characteristic group frequencies. In Infrared and Raman Spectroscopy-Principles and Spectral Interpretation; Elsevier: Amsterdam, The Netherland, 2011; pp. 73-115.

77. Cao, B.; Shi, L.; Brown, N.R.; Xiong, Y.; Fredrickson, K.J.; Fomine, F.M.; Marshall, M.J.; Lipton, M.S.; Beyenal, H. Extracellular polymeric substances from Shewanella sp. HRCR-1 biofilms: Characterization by infrared spectroscopy and proteomics. Environ. Microbiol. 2011, 13, 1018-1031. [CrossRef] [PubMed]

78. Sano, K.; Kanematsu, H.; Hirai, N.; Tanaka, T. Preparation and its anti-biofouling effect observation of organic metal dispersed silane based composite coating. J. Surf. Finish. Soc. Jpn. 2016, 67, 268-273. [CrossRef]

79. Ogawa, A.; Kiyohara, T.; Kobayashi, Y.H.; Sano, K.; Kanematsu, H. Nickel, moluybdenum, and tungsten nanoparticle-dispersed alkylalkoxysilane polymer for biomaterial coating: evaluation of effects on bacterial biofilm formation and biosafety. Biomed. Res. Clin. Pract. 2017, 2, 1-7. [CrossRef]

80. Nyquist, R.A. Interpreting Infrared, Raman, and Nuclear Magnetic Resonance Spectra; Academic Press: San Diego, CA, USA, 2001.

81. Hamasha, K.M. Raman Spectroscopy for the Microbiological Characterization and Identification of Medically Relevant Bacteria. Ph.D. Thesis, Wayne State University, Detroit, MI, USA, 2011.

82. Rzhepishevska, O.; Hakobyan, S.; Ruhal, R.; Gautrot, J.; Barbero, D.; Ramstedt, M. The surface charge of anti-bacterial coatings alters motility and biofilm architecture. Biomater. Sci. 2013, 1, 589-602. [CrossRef]

(C) 2018 by the authors. Licensee MDPI, Basel, Switzerland. This article is an open access article distributed under the terms and conditions of the Creative Commons Attribution (CC BY) license (http:/ / creativecommons.org/licenses/by/4.0/). 